\title{
Methods to improve the capitalization level of enterprises
}

\author{
Olga Anichkina ${ }^{*}, 1$, Irina Bogonosova $^{1}$, Larisa Prykina $^{2}$, Tatyana Dubrovskaya ${ }^{3}$ and Aleksey \\ Zaretskikh $^{3}$ \\ ${ }^{1}$ Moscow state University of technology and management. K.G. Razumovsky, Zemlyanoy Val street, \\ 73, 109004, Moscow, Russia \\ ${ }^{2}$ Moscow State University of Civil Engineering, Yaroslavskoye shosse, 26, 129337, Moscow, Russia \\ ${ }^{3}$ Voronezh State Technical University, Moscow Avenue, 14, 394026, Voronezh, Russia
}

\begin{abstract}
The purpose of the study is to identify and systematize the capitalization methods of enterprises in the construction industry by analyzing of internal and external expansion. The paper analyzes models of capitalization with vertical and horizontal integration in the cluster structure, considers factors of growth of capitalization through cluster structures that have the greatest potential for innovative development. They ensure effective binding of internal resources in the innovative development projects, while using external sources of growth as fully as possible. As a result of the study, the algorithm was developed to form and implement the capitalization mechanism of activity of construction enterprises on the basis of the implementation concept of new forms of activity.
\end{abstract}

\section{Introduction}

Enterprises should expand their activities to keep competitive positions in the market and increase the capitalization level. In case the enterprise is unable to development, then its competitors will be able to steal the most of market share, and it will negatively affect the capitalization. The growth of the enterprise is an indispensable element of the survival strategy, especially if it plans to successfully implement a number of changes and operates under conditions of environmental uncertainty [1].

An enterprise that strives to increase its capitalization carries out activities to expand its market share, both local and international, which is directly related to the increase of production capacity. The solution of this task is the implementation of strategies for internal and external expansion.

\section{Materials and methods}

\footnotetext{
* Corresponding author: f-1980@ya.ru
} 
Internal expansion is a strategy in which enterprise pursues a policy to expand its production capabilities by increasing its existing production capacities or constructing new production complexes.

There are three ways of internal expansion of the enterprise:

- horizontal integration - an enterprise within existing markets produces a variety of products through a similar or related process that provides it with economies by the diversification of production.

- vertical integration implies the expansion of activities of the enterprise in the existing market.

- heterogeneous diversification is the expansion of its activities by entering other markets and changing the current range of products.

The scheme of increase of capitalization through the internal expansion is shown in Fig. 1.

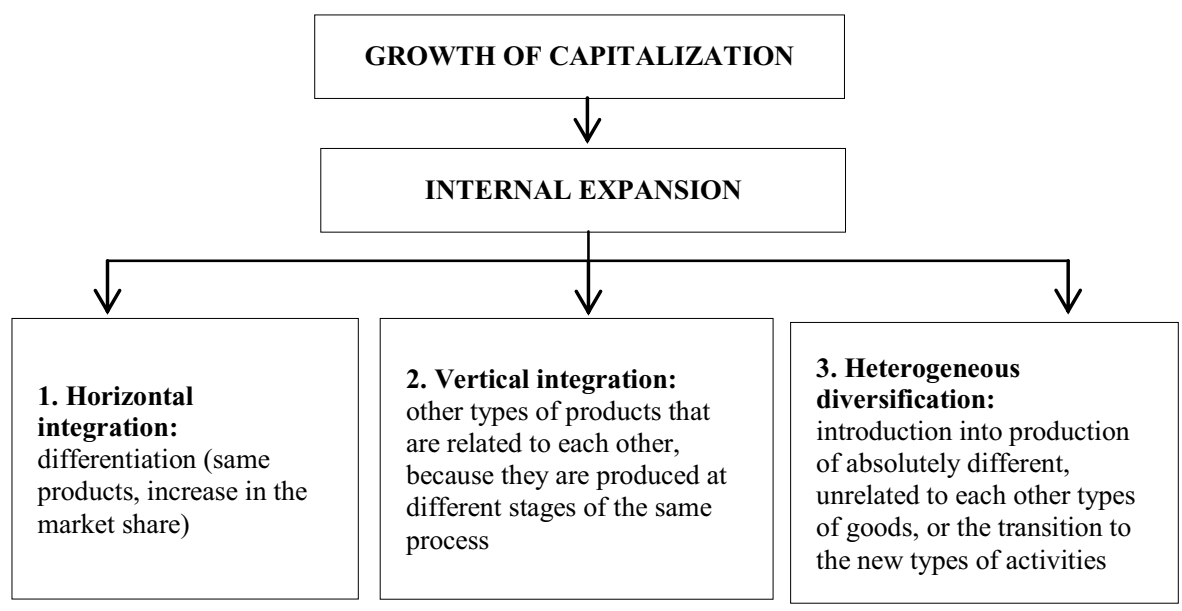

Fig. 1. Growth of capitalization through the internal expansion.

External expansion is a strategy in which the growth of capitalization is achieved through merger or acquisition by another enterprise operating in the same market or within the same industry, or through creation of strategic alliance with one or more enterprises. External expansion, irrespective of the form of its implementation, can be vertical or horizontal, just like internal expansion, and also imply diversification [2]. The scheme of increase of capitalization through the external expansion is shown in Fig. 2. 


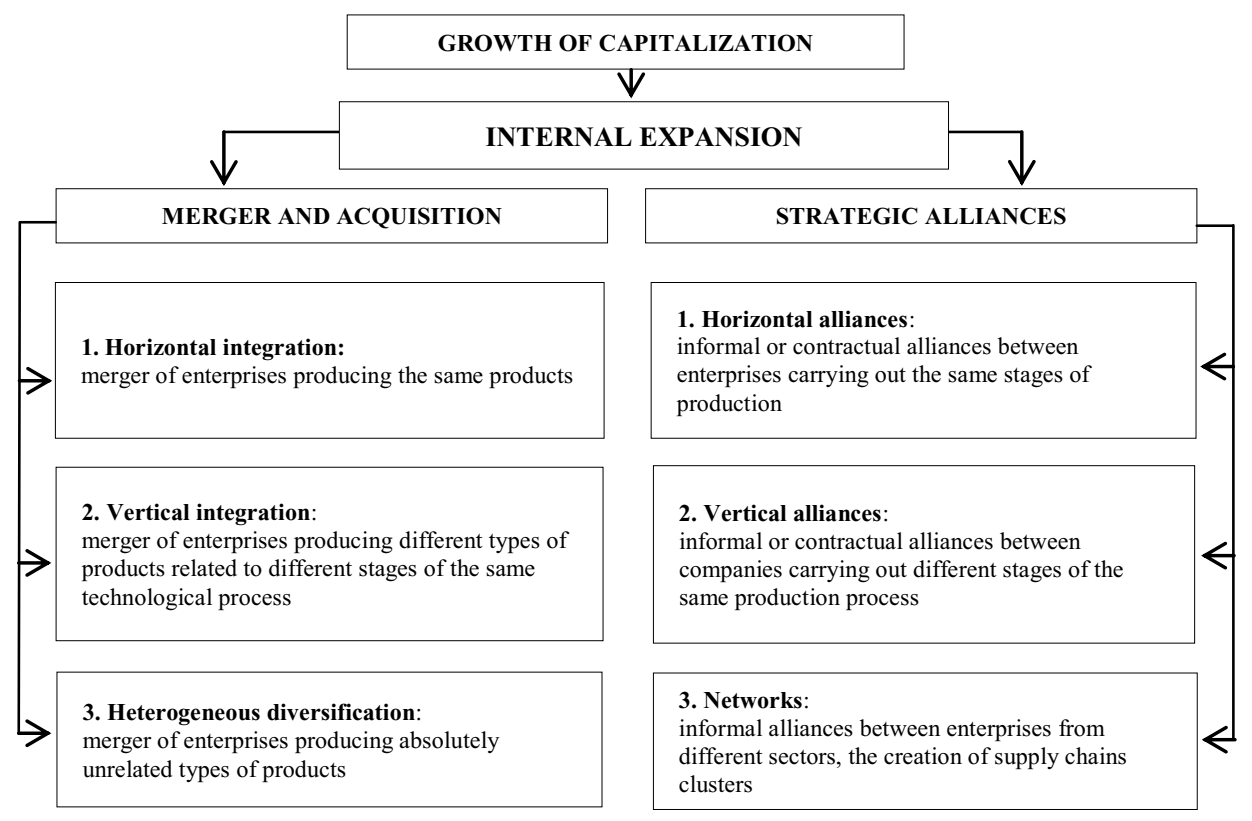

Fig. 2. Growth of capitalization through the external expansion.

In practice, the use of merger or acquisition mechanisms leads to an increase of power over the market and the market value of the enterprise, as well as to reduction of average costs and probability of being absorbed.

It should be noted that formation of a strategic alliance plays an important role for capitalization. This term is used to indicate the variety of cooperation agreements. It means the creation of a joint venture for the implementation of a specific project or the production of a certain product, and may also imply the conclusion of an informal agreement on the supply or sale of goods [3].

The final and most important mechanism for external expansion are the networks of enterprises.

Networks are an alliance of several enterprises from different sectors, while the agreements between these enterprises can be both formal and informal. Belonging to the network provides the enterprise with access to technology, resources and the global market. The creation of networks helps to achieve a competitive advantage by its core activities and other, less formal, means.

The creation of a cluster in construction is stems from the fact that the construction and installation enterprise couldn't conduct the whole complex of works on the creation of finished construction products through its own efforts. This type of enterprise network promotes the development of scientific-research and development works as a separate and an integral part of the cluster.

The cluster forms the environment with an interest in the development of innovations, since only its own scientific-research and development results allow producing of competitive product. It ensures the maximum profit per unit of investment and therefore is the key to a stable growth of capitalization. The transition of the construction industry to an innovative type of development is an indispensable factor for determining the transition of the enterprise to a high level of capitalization and sustainable economic growth. 
Joining the cluster increases the efficiency of the construction enterprise, contributes to the rationality of production and market processes, the redistribution of risks and the implementation of flexible policies required in the rapidly changing market conditions.

The primary motive behind the enterprise's management about the usefulness of the participation in the cluster structure is the possibility to obtain the synergetic effect that provides greater amount of profit than with its independent operation on the market. Consequently, the level of capitalization within the cluster will be noticeably higher [4].

Assessment of the synergistic effect is one of the main approaches to assessing the effectiveness of the operation of cluster structures in the process of capitalization. The effect of synergy in cluster enterprises arises from the fact that within the framework of cluster structures the links between the participants are being streamlined and developed, becoming more close and productive. Therefore, the exchange of resources is facilitated in clusters. The information circulates more quickly within the cluster network, which allows the cluster participants to quickly and adequately respond to changes in the external and internal environment, take more balanced and effective decisions. The developed relationships of the cluster participants enable implementation of the joint projects. There are two main technologies for the creation of clusters that distinguished in modern foreign and domestic scientific literature: vertical and horizontal.

With vertical integration of a cluster of construction enterprises, the sub-contracting and outsourcing relationship is the basis of the capitalization activity mechanism (Fig. 3). These relations have hierarchical nature with pronounced dominant leader. Competition among suppliers in the cluster structure is generally not available because they supply different products or provide various services. Geographic proximity of enterprises contributes to the capitalization of activities in general for the cluster, as well as for individual enterprises [5].

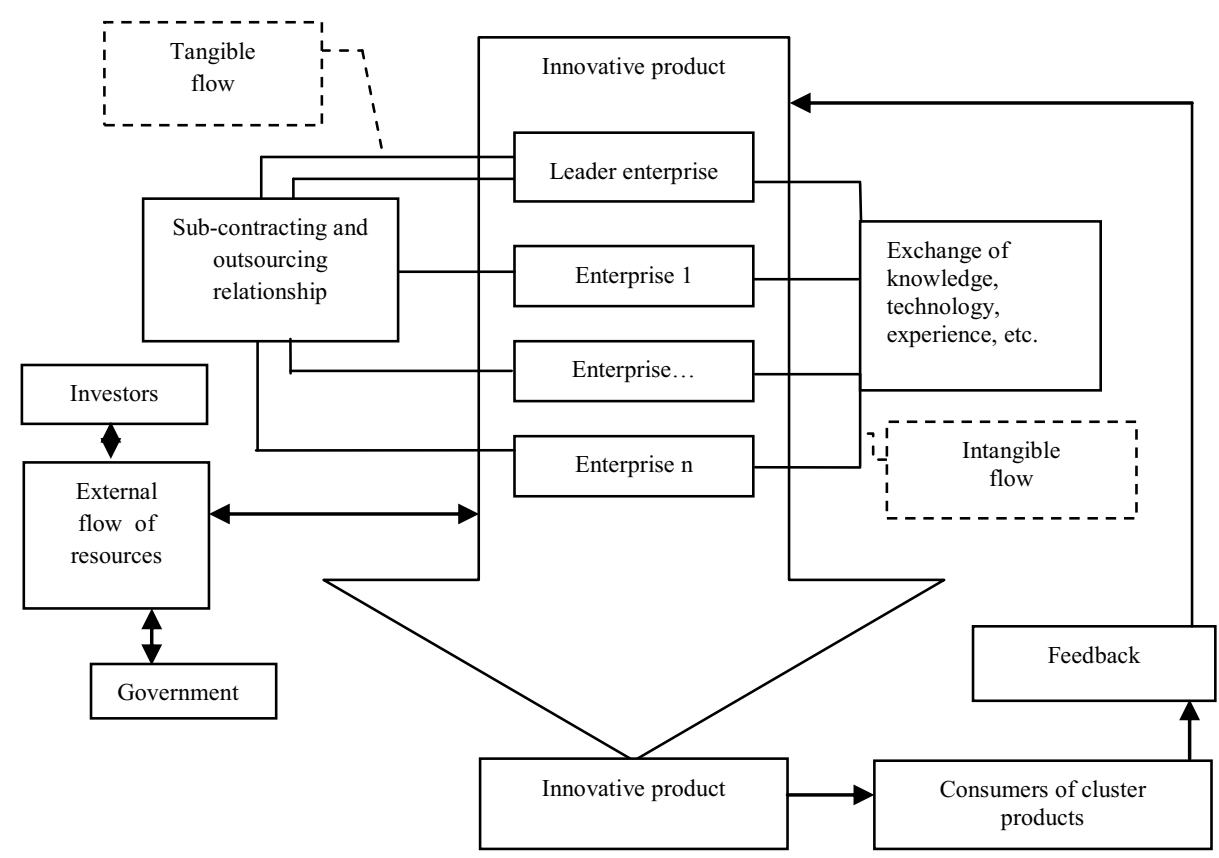

Fig. 3. The model of capitalization with vertical integration in the cluster structure.

With horizontal integration of the cluster, the unified technological chain of obtaining the value addition is formed. Typical connections for this integration are the ones in which each subsequent subject is a consumer of the product of the previous one. Capitalization of activities with horizontal integration is achieved as a result of saving the value of 
production and marketing costs, increasing the reliability of supply of products and improving quality control (Fig. 4).

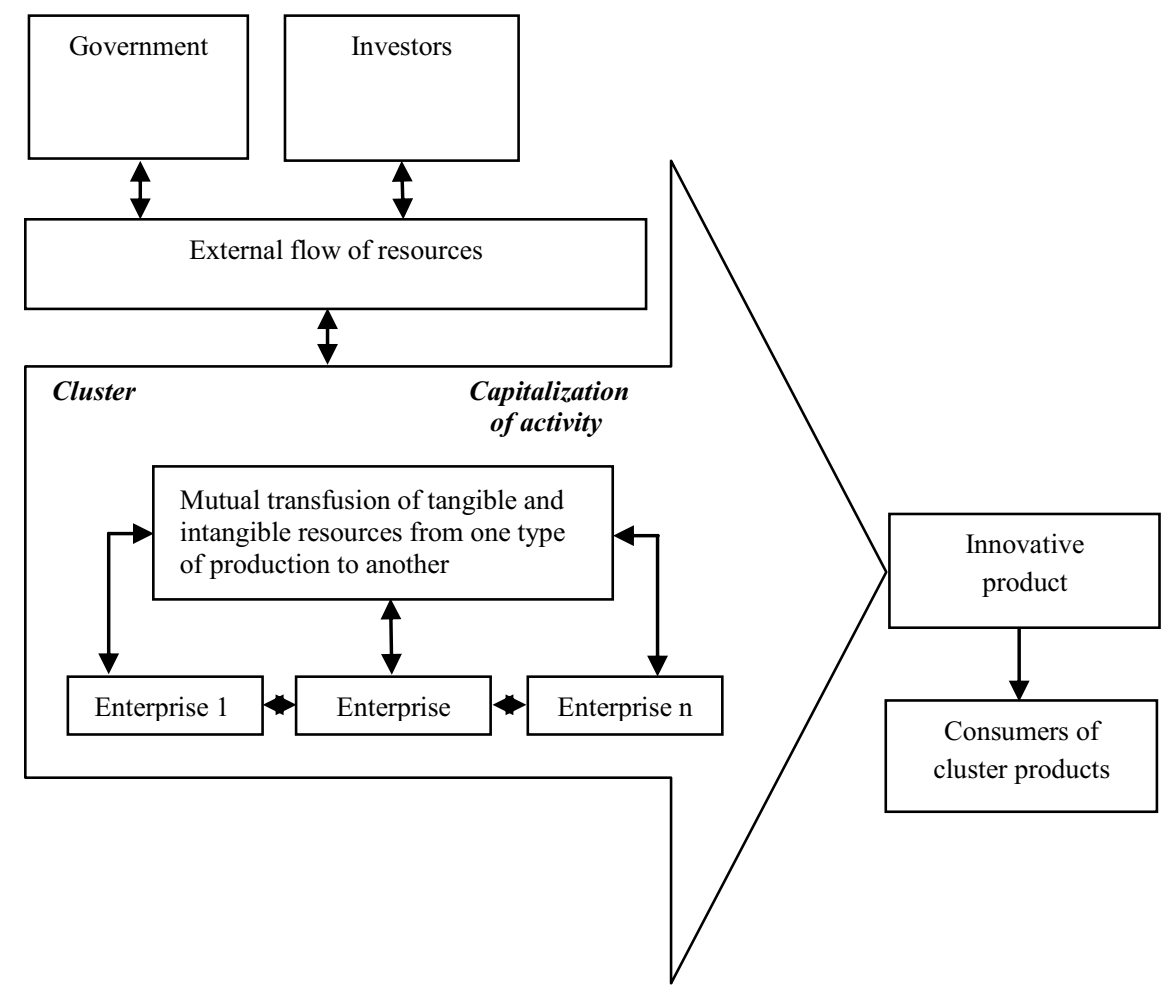

Fig. 4. The model of capitalization with horizontal integration in the cluster structure.

Based on the above, the algorithm was developed for the formation and implementation of a mechanism for capitalization of activity of the construction enterprises (Fig. 5). The concept for the development of an algorithm for the capitalization mechanism by the implementation of new forms of activity is based on the following postulates.

The existence of an adjusted strategy of the enterprise characterizes the understanding by its management of the main objective of the organization development, the directions of capitalization of its assets, as well as the means and mechanisms for their implementation [6].

The imperatives of modernization and innovation of the construction sector of the national economy are directly related to the improvement of approaches to the formation of methods and mechanisms for the strategic management of the construction enterprise development.

The level of capitalization of the enterprise's activity in the cluster structure is increased as a result of the possibility of rational and operative redistribution of the resources of cluster entities into the most promising areas of business development.

It is necessary to solve the problem with the development of a methodology for the assessment of the capitalization of construction enterprises, since today the possibility of a professional assessment of the level of capitalization is faced with the absence of adapted methods.

\section{Discussion}


At the first stage information should be collected and analysis of the external and internal environment should be conducted to select development strategy for the construction company. It is necessary to assess the stability of the economy in the country and on the global market in general. And it is also important to determine the internal potential of the enterprise.

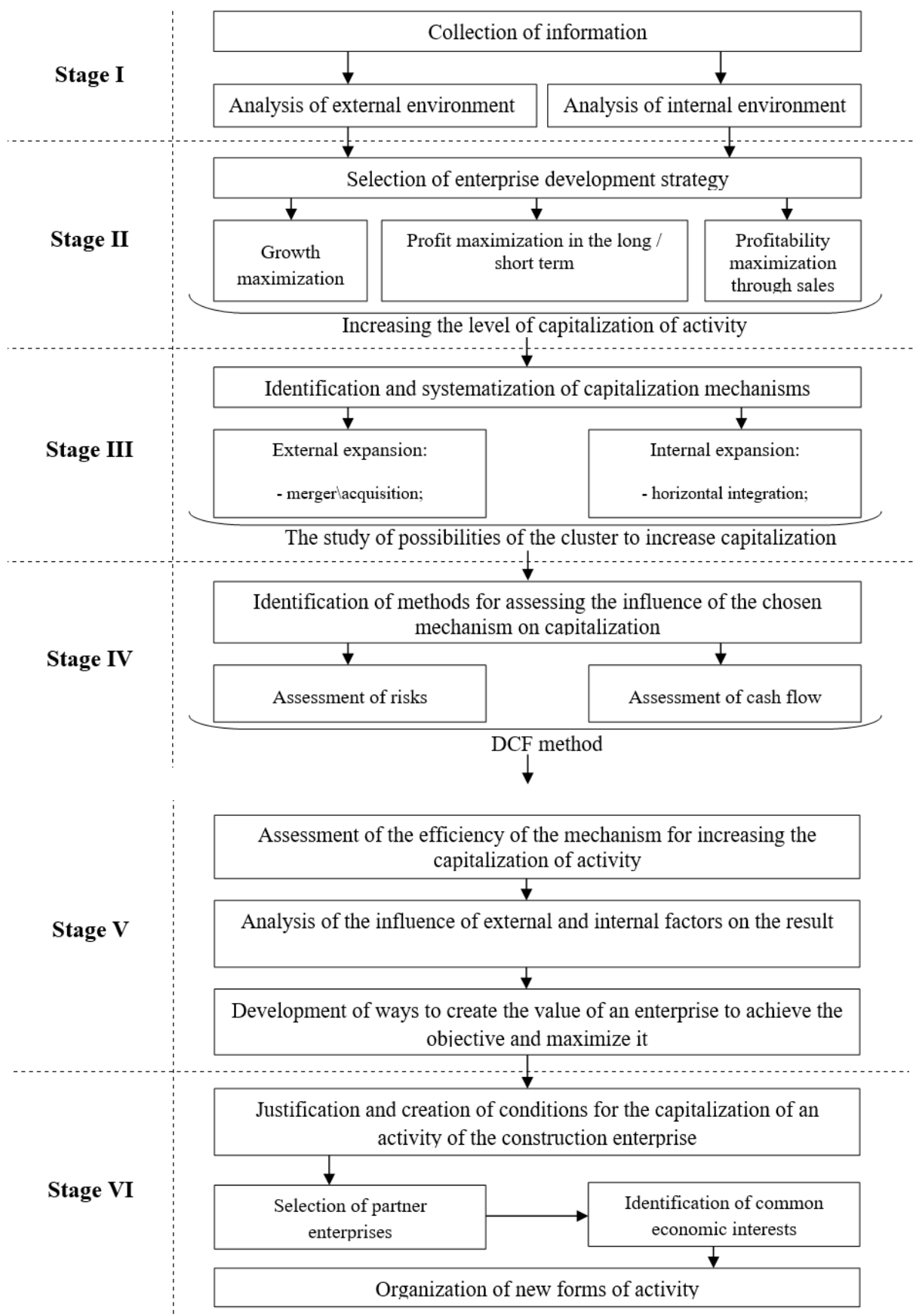

Fig. 5. The algorithm for the mechanism of capitalization of activity of the construction enterprises on the basis of realization of new forms of activity. 
At the second stage the construction enterprise must choose a strategy for its development based on the analysis received. The multiplicity of enterprise strategies converges to one objective - increasing the level of capitalization of their activities. It should be noted that in each strategy there is a rational analysis that helps to predict the future, as well as assess the consequences [7].

At the third stage the construction enterprise needs to determine the mechanism by which the strategy chosen at the second stage will be implemented. The advantage of the cluster is that it facilitates the exchange of resources among the enterprises, which helps to increase the efficiency of their use.

At the fourth stage the level of capitalization of the construction enterprise is assessed by estimating its value within a cluster formation. An analysis of domestic scientific literature, as well as practical experience, has shown that the best method of this assessment is the DCF method.

At the fifth stage of the algorithm the effectiveness of the mechanism for increasing the capitalization of activity of the construction enterprise is assessed. Methods are applied to minimize the negative influence on the result obtained by analyzing the influence of external and internal factors.

At the sixth stage an organizational model is being developed to justify and create conditions for the capitalization of activity of the construction enterprises.

\section{Conclusion}

The study has shown that the processes of capitalization of enterprises of the construction industry can be most effectively realized through integration in the form of cluster formations. With the operating construction cluster the novelty of the study was the proposal of ways to integrate the enterprise into the existing cluster association, the formation of a fundamentally new target orientation for the use of cluster resources and the creation of a system of new economic relations.

\section{References}

1. E. Nezhnikova, O. Papelniuk, A. Gorokhova, International Journal of Energy Economics and Policy 8(1), 203-211 (2018)

2. V. Kankhva, MATEC Web of Conferences 106, 08027 (2017) doi.org/10.1051/matecconf/201710608027

3. A. Pustovgar, L. Shilova, A. Adamtsevich, I. Garanzha, A. Tanasoglo, V. Ivanilov, Procedia engineering, 165 (2016) DOI:10.1016/j.proeng.2016.08.193

4. A. Solovyev, Pustovgar, L. Shilova, A. Adamtsevich, D. Solovev. Procedia Engineering, 165 (2016) DOI:10.1016/j.proeng.2016.11.850

5. A. Borboni, M. Lancini, (2015) Journal of Vibration and Acoustics, Transactions of the ASME 137(3), A1, DOI:10.1115/1.4029575

6. I.V. Ilin, O. Kalinina, O. Iliashenko, A. Levina, Procedia Engineering 165, 1683- 1692 (2016) doi: 10.1016/j.proeng.2016.11.910

7. I.G. Lukmanova, M.Y. Mishlanova, International Journal of Economics and Financial Issues 5, 208-216 (2015) 